\title{
Historia de una enfermedad: Der Alpdruck de Hans Fallada y la identidad alemana frente a la herencia nacionalsocialista
}

\author{
[History of a disease: Hans Fallada's Der Alpdruck and the German identity in the light \\ of National Socialist heritage] \\ http://dx.doi.org/10.11606/1982-88372444400
}

Ricardo Andrade ${ }^{1}$

\begin{abstract}
This article explores a forgotten novel in Hans Fallada's literary production: Der Alpdruck. This novel, testimony of the suffering and hope of German society in the first years after World War II, explores the heritage of National Socialism in individual and collective life. Central concepts such as roots, identity and language become central elements to understand the consequences of political terror and the pain of an existence devoid of affective and reflective horizons. The article dwells on these concepts, analyzing some chapters of the novel to demonstrate the permanence of National Socialism in various aspects of the subjects, and the attempt to deal with this heritage in order to think Germany.
\end{abstract}

Keywords: National Socialism; Contemporary German literature; Hans Fallada; Identity; Literary theory.

Resumen: El presente artículo explora una novela olvidada en la producción literaria de Hans Fallada: Der Alpdruck. Esta novela, testimonio del sufrimiento y la esperanza de la sociedad alemana en los primeros años posteriores a la Segunda Guerra Mundial, indaga en la herencia del nacionalsocialismo en la vida individual y colectiva. Conceptos centrales como el arraigo, la identidad y el lenguaje se transforman en elementos centrales para comprender las consecuencias del terror político y el dolor de una existencia desprovista de horizontes afectivos y reflexivos. El artículo se detiene en dichos conceptos tomando algunos capítulos de la novela para evidenciar la permanencia del nacionalsocialismo en diversos aspectos de los sujetos y el intento de lidiar con dicha herencia para pensar Alemania.

Palabras clave: Nacionalsocialismo; Literatura alemana contemporánea; Hans Fallada; Identidad; Teoría literaria.

\footnotetext{
${ }^{1}$ Universidad de Buenos Aires, Facultad de Filosofía y Letras, Puan 480, C1406, Buenos Aires, Argentina. E-mail: andrader218@gmail.com. ORCID: 0000-0002-6422-0809
}

\section{(cc) BY-NC}




\section{Albores del horror: breve introducción a la obra del autor}

\section{durante el nacionalsocialismo}

Una aproximación a Der Alpdruck debe ser entendida en el marco de la producción literaria de Hans Fallada (nacido con el nombre de Rudolf Wilhelm Friedrich Ditzen) y su íntima relación con los problemas sociales, políticos y económicos de la República de Weimar y el ascenso del nacionalsocialismo. La primera obra de Fallada que explora las turbulencias políticas y sociales de la Alemania de la posguerra es Bauern, Bonzen und Bomben (1931). Esta novela, que toma como base los acontecimientos suscitados entre 1928 y 1929 en Schleswig-Holstein a raíz de la resistencia campesina del movimiento Landvolkbewegung a los embargos de sus medios de producción por parte del gobierno regional, evidencia ya una preocupación constante del escritor: la de darle voz, a través de la ficción, al decaimiento de los principios civilizatorios burgueses y liberales en la sociedad alemana. A su vez, destaca un elemento central dentro de la poética falladiana: la recuperación de las vivencias sociales y los materiales periodísticos e históricos para elaborar una crítica concisa y eficaz anclada en la cotidianidad del lector. Esta aproximación a la realidad desde lo ficcional está íntimamente involucrado con el auge del reportaje y la Dokumentarliteratur que buscan, a través de lo concreto, realzar los elementos objetivos que conforman una situación social e individual (la ya citada novela se nutre, precisamente, de las investigaciones periodísticas del propio Fallada). El auge de esta hibridación entre literatura y periodismo se halla en el intento, por parte de los escritores, de luchar contra el psicologismo y, en última instancia, contra algunas posturas irracionalistas (el auge del impulso dionísiaco de la filosofía nietzscheana y la exacerbación del ocultismo son algunos ejemplos) que en la Alemania de la posguerra adquirían un peso considerable. A pesar de esto y con respecto a la influencia de estos elementos en la literatura, György Lukács señala que

El reportaje como método creativo nació como justificada oposición a tales ideologías y a sus formas. Los escritores de oposición que mantenían relaciones más o menos estrechas con el movimiento obrero, intentaron describir de forma objetiva y fiel a la realidad los abusos de la sociedad capitalista que condenaban. El punto de partida primario de esta corriente era una postura distinta frente a la sociedad capitalista por parte de los representantes de la novela psicológica: la postura de una oposición radical pequeñoburguesa, que en ocasiones rozaba el socialismo (LUKÁcs 2002: 207).

Esta reflexión lukácsiana permite vislumbrar la noción de escritor en la época de Fallada. La crisis de los valores, que conlleva a una inestabilidad en la forma, deviene en 
una crítica hacia el sistema capitalista y las consecuencias que acarrea en la vida social. En la novela ya citada, el autor busca entender los mecanismos que despojan a los sujetos de sus propios medios de subsistencia y los llevan hacia la rebelión, el fascismo o el terrorismo. Los abusos del sistema, en este sentido, se concretizan a través de una violencia sin tregua, en donde la instauración de la lucha es el germen que dará paso a la consolidación del nacionalsocialismo. Otro elemento a destacar es el énfasis que realiza Lukács en la condición pequeño-burguesa de estos escritores. El caso de Fallada puede tomarse como un ejemplo de ello, tanto por su formación familiar (su padre era un magistrado), como la profesional (redactor en distintos periódicos). Además de ello, su poca interacción con los conflictos del proletariado alemán y la política en general a causa de sus problemas personales (su famosa adicción a las drogas y al alcohol) lo mantienen anclado en la Kulturpessimismus característica de la burguesía alemana. Un año después de la publicación de Bauern, Bonzen und Bomben, Fallada logra consagrarse como un escritor relevante dentro del mundo literario e intelectual alemán con su famosa novela Kleiner Mann - was nun? (1932). El año de publicación de la novela no es fortuita, ya que ese mismo año el NSDAP logra posicionarse como el primer partido de Alemania en las elecciones legislativas. La novela narra las vicisitudes del joven Johannes Pinneberg en el turbulento período de la Gran Depresión, la miseria material y el decaimiento de la vida producto del quiebre del sistema económico capitalista. Además de esto, hace aparición otro elemento importante de la poética falladiana: la metrópoli (Berlín) se transforma en la gran protagonista también. La importancia de la ciudad radica en que logra desenvolver todos los anhelos y el desencanto característicos no solo de la industrialización, sino también del desarrollo de la noción de trabajo y la alienación fetichizada del mundo capitalista. La volatilidad de la urbe deviene, de este modo, en una nueva religiosidad disoluta de los valores constitutivos del yo burgués. El dinamismo de la novela tiene relación con el desarrollo estilístico de la "Asphaltliteratur" (literatura del asfalto) nacida de la Neue Sachlichkeit (Nueva objetividad). Con respecto a este concepto, se puede añadir que

Die Attitüde der «Asphaltliteratur» besetzt den Pol von «Mobilität/Kälte/Vergessen». Ziemlich abrupt wird die vertraute Entfremdungsklage der Lebensphilosophie in ihr Gegenteil verkehrt. Das alte Stereotyp vom «Wunschbild Land - Schreckbild Stadt» wird umgepolt: «es befriedigt, diesen blankgewichsten Asphalt zu sehen. Das Benutzte ist erfreulich; es ist eine Parabel der Aktualität» (Wilhelm Hausenstein 1929). [222; S. 180]. An die Stelle des Schreckens von der Standardisierung tritt die Entdeckung der Schönheit des industriellen Serienprodukts. Die Anonymität der Großstadt wird als Schutz vor familiärer und staatlicher Überwachung begrüßt. «Verwurzelt» ist nur das Opfer (LETHEN 1983: 173). 
ANDRADE, R. - Der Alpdruck de Hans Fallada

La fascinación por la ciudad es clave para entender también la reacción contra algunas posiciones ideológicas del nacionalsocialismo, entre ellas el Blut und Boden o el énfasis en los valores rurales anclados en una tradición mitificada y fetichizada. En este sentido, Fallada en Kleiner Mann - was nun? no solo elabora una crítica a las condiciones de vida paupérrimas en la República de Weimar, sino también ataca, de manera velada, las corrientes irracionalistas imperantes a través del esplendor y la miseria de la vida urbana. Visto desde esta perspectiva, lo que Fallada realza críticamente son los vaivenes del burgués y el pequeño-burgués, de manera que con la novela se transforma en un narrador de las ilusiones de la clase media en un sistema que anula las aspiraciones de los sujetos hasta transformarlos en objetos. Se debe añadir a esta reflexión un evento asociado a la novela que no es menor: la aparición de una película basada en la obra en 1933 bajo el amparo de los medios propagandísticos nacionalsocialistas. A pesar de algunas censuras realizadas, la película funcionó como medio para desacreditar a la ya moribunda República de Weimar en el plano espiritual, material y social. En este punto ya se evidencia lo que será la compleja relación de Fallada con el régimen, marcada por la ambigüedad política.

En 1937 se publica Wolf unter Wölfen, obra de gran relevancia en la historia literaria de Fallada. Lo que destaca esta novela, de manera similar a Kleiner Mann - was nun?, es la ruina de la sociedad alemana a partir de la Primera Guerra Mundial. Los nacionalsocialistas, para esta fecha, tienen el poder absoluto de Alemania al haber sido elegido Adolf Hitler en 1933 como canciller y al haber provocado el famoso incendio del Reichstag en el mismo año. La particularidad política de esta novela radica en el enorme apoyo que recibió por parte de Joseph Goebbels, al ser utilizada como un ejemplo literario de la decadencia de Alemania gracias a la derrota sufrida en la Gran Guerra. A pesar de este apoyo expreso y al intento de Goebbels de transformarlo en un escritor afín a las políticas estatales, Fallada se mantiene al margen de cualquier posición abierta que favorezca al régimen. A partir de este momento, comienza lo que se puede llamar como su "innere Emigration", de forma que su obra pasa a formar parte de una "Literatur der inneren Emigration" particular dentro de la historia intelectual y literaria alemana, ya que Fallada decide quedarse y padecer las consecuencias del régimen nacionalsocialista. Este concepto es ampliamente problemático, ya que está atravesado por la ambigüedad política (la historia del término está relacionada con el intento de ocultar el colaboracionismo explícito e implícito bajo una forma de supuesta resistencia clandestina) y contrarresta con la noción de Exilliteratur y la experiencia vital de aquellos que decidieron abandonar 
Alemania. Con respecto a esta noción, señala pertinentemente Bettina Bannasch que

Die problematischen Implikationen des Begriffs ,Literatur der Inneren Emigration“ lassen sich somit in dreifacher Hinsicht präzisieren: Erstens verwischt der Begriff die Unterschiede zwischen Autorinnen und Autoren, die Deutschland verließen und deren Schreiben unter prinzipiell anderen Bedingungen stattfand als das jener Autorinnen und Autoren, die in Deutschland blieben und dort veröffentlichen konnten. Er konstruiert eine scheinbare Entsprechung von innerer und äußerer Emigration. Zweitens legt der Begriff der Inneren Emigration ein Moment der Freiwilligkeit nahe. Diese Akzentuierung wird vorgegeben durch die Verwendung des Begriffs Emigration anstelle von Exil. Vernachlässigt werden damit die prinzipiell unterschiedlichen Handlungsspielräume, die für ,arische' und für jüdische Autorinnen und Autoren bestanden. Die Vernachlässigung dieser Differenz hatte weitreichende Folgen für die Wahrnehmung bzw. NichtWahrnehmung der Literatur, die von jüdischen Autorinnen und Autoren nach 1933 in Deutschland verfasst wurde. Die Beschäftigung mit ihrer Literatur setzte mit deutlicher Verzögerung ein - dies gilt selbst noch für Gertrud Kolmar, die prominenteste Vertreterin dieser Gruppe, deren Werk erst zu Beginn der 1980er Jahre eine breitere Aufmerksamkeit zuteil wurde. Drittens schließlich hat der Begriff ,Literatur der Inneren Emigration“ Folgen für das Verständnis von Exilliteratur selbst. In der oppositionellen Setzung von Exil und Emigration wird, gewissermaßen ,unter der Hand', aus der Exil- eine Emigrantenliteratur. Bertolt Brechts Gedicht Über die Bezeichnung Emigranten macht auf die Problematik dieser begrifflichen Gleichsetzung bereits 1937 aufmerksam (BANNASCH 2013: 50-51).

Esta reflexión recupera la paradoja de definir un período literario y político-social marcado por la incertidumbre y el desarraigo. La figura de Fallada no puede ser considerada como clandestina ya que, como se ha observado, Goebbels insistió en incluirlo dentro de los autores vinculados a los ideales nacionalsocialistas. Tampoco el autor escribió críticamente contra el régimen. A su vez, no existe una relación entre las producciones literarias de los exiliados y los que decidieron permanecer. Fallada decide volcarse hacia la producción de obras infantiles y de memorias para evitar incomodar y atacar directamente al régimen, de manera que la discontinuidad en cuanto a la crítica a las condiciones sociales es patente por el peso de la ambigüedad política a excepción de Der eiserne Gustav (1938) que mantiene aun el espíritu crítico en relación con la Primera Guerra Mundial y sus consecuencias. Si se parte de este punto, la noción de "Literatur der inneren Emigration" debe pensarse en función de la experiencia personal de los autores y bajo la premisa de ser un concepto que tiende más a tratar de ocultar las relaciones políticas de los escritores con el nacionalsocialismo, de manera que deviene en una noción que busca hacer desaparecer la historia de los horrores en pos de una "resistencia". Sin embargo, y a pesar de la complejidad de este término, el mismo señala un elemento a considerar: la muerte política de la República de Weimar y el afianzamiento del aparato represivo que implicó una destrucción de la herencia literaria e intelectual gestada en el período de entreguerras. En el caso de Fallada, ser testigo directo de esta 
ANDRADE, R. - Der Alpdruck de Hans Fallada

destrucción significó observar los procesos de disolución del yo individual, de la vida civil y del discurso literario en nombre de la la política total nacionalsocialista. En 1944, y en una situación confusa y accidental, las autoridades consideran que ha intentado matar a su ex esposa y es recluido en un sanatorio mental. De esta experiencia escribe Der Trinker (1944), obra que será publicada después de su muerte. Al tener en consideración estas experiencias, la decisión de Fallada de permanecer en Alemania adquiere un mayor signo de profundidad, ya que ese ser testigo es el origen de sus dos novelas de la posguerra de 1945: Der Alpdruck y Jeder stirbt für sich allein (1947). Ambas novelas pertenecen ya a la Nachkriegsliteratur (literatura de la posguerra). La última novela citada es importante en múltiples sentidos. El primero radica en la enorme popularidad que obtuvo en su momento, al ofrecer una reflexión sobre el coraje y la resistencia ante el nacionalsocialismo por parte de Otto y Elise Hampel, ambos ejecutados por incitar a la sublevación contra Hitler a través de postales en plena Segunda Guerra Mundial. La fama de la novela se mantiene en la actualidad, ejemplo de ello son las constantes reediciones en alemán, las traducciones a numerosos idiomas (por ejemplo, al japonés o al farsi) especialmente a partir del año 2010 hacia adelante y las películas realizadas hasta la fecha (la primera en el año 1962 y la última en el año 2016). El segundo elemento tiene relación con la recuperación que hace Fallada de hechos de la vida real para la elaboración de su obra, de forma que retoma su antiguo método de escritura para darle voz a la dignidad humana en medio de la destrucción. Es interesante destacar que, en términos históricos, ambas novelas se publican en lo que se conoce en la historia de la literatura alemana como la Trümmerliteratur (literatura de escombros). Esta noción, como categoría literarioexistencial, es adecuada para este tipo de apropiaciones de lo real. Desde los escombros se puede pensar en resistir y en darle espacio a aquellos que la historia olvidaría si la ficción no funcionara como lugar de enunciación de la memoria. Si bien en la historia de la literatura alemana este concepto tiene unos elementos bien definidos en términos formales (la brevedad, lo fragmentario) y que Fallada no es incluido usualmente por la crítica como un representante del movimiento, las novelas de la posguerra del autor exploran, en términos de contenido, las consecuencias y las preocupaciones de la disolución del lenguaje, la política y la vida individual y social después del nacionalsocialismo. El hecho de que el género novelístico sea la forma para expresar dicha destrucción llama la atención en un período histórico donde la mudez, la infertilidad del lenguaje y el horror ante la vida despojada de todo sentido es el panorama anímico de los alemanes. Como se verá en la siguiente parte del presente artículo, estas exploraciones 
ANDRADE, R. - Der Alpdruck de Hans Fallada

permiten repensar a Fallada en el marco de la Trümmerliteratur a través de Der Alpdruck, logrando de este modo actualizar la poética del autor para futuros análisis y debates.

Esta breve introducción a la obra falladiana durante el nacionalsocialismo (que funciona también como presentación de una época oscura en la historia alemana) permite introducir la obra a estudiar en el presente artículo: Der Alpdruck. Esta novela que ahonda, con rasgos autobiográficos, en la experiencia de la derrota y la desolación de los primeros meses de la posguerra, es el alegato de Fallada ante las consecuencias del terror político en la vida de los ciudadanos. Si se compara la popularidad de la que goza Jeder stirbt für sich allein con la poca atención que recibió Der Alpdruck, el estudio de esta última es de vital importancia no solo para comprender el desarrollo de la poética falladiana, sino también para acercarse a una sociedad destruida desde sus cimientos que busca, de distintas maneras, sobrevivir ante la catástrofe a través de la literatura hecha memoria.

\section{Del terror político a la desoladora esperanza: análisis de la}

\section{novela}

El régimen nazi sucumbe en 1945 con la llegada de las tropas soviéticas en el frente este y por las tropas angloamericanas en el frente oeste. Ese mismo año, Alemania es dividida en cuatro administraciones: la soviética, la estadounidense, la británica y la francesa. La penuria material viene aparejada con la respuesta ambigua de los ciudadanos alemanes ante la llegada de los Aliados. Por una parte, existe la constatación de la inminente derrota; por otro lado, la sombra del hitlerismo aun tiene un peso fundamental en la vida social. Fallada escribe Der Alpdruck en un corto tiempo: entre febrero y agosto de 1946, mientras se encontraba internado entre hospitales y sanatorios mentales. La trama de la novela se centra en las experiencias del escritor Dr. Doll y su esposa Alma (alterego de Fallada y su por entonces segunda esposa) en las ruinas de la Alemania de la posguerra. Ambos personajes, mientras van sucediendo los acontecimientos, cambian de locaciones que van desde una ciudad pequeña de cerca de Prenzlau hasta el corazón del ya derrotado Reich: Berlín. De esta forma, Fallada abarca la ruina de la vida alemana en toda su amplitud y su respectivas consecuencias. En este sentido, lo primero que llama la atención de la novela es su prólogo. En él, el autor escribe la siguiente reflexión:

El autor de esta novela no está en modo alguno satisfecho con lo que escribió en las páginas que el lector tiene ahora impresa ante sus ojos. Cuando concibió este libro, tenía 
ANDRADE, R. - Der Alpdruck de Hans Fallada

en mente que, además de las derrotas de la vida cotidiana, las depresiones, las enfermedades, el desaliento... Que, a pesar de todos estos fenómenos que el final de la espantosa guerra supuso inevitablemente para todo alemán, también había que escribir nuevos impulsos: hechos de gran valentía, horas llenas de esperanza... Pero no lo consiguió. El libro ha quedado, en lo esencial, como el informe de una enfermedad, la historia de esa apatía que acometió a la mayor parte $-\mathrm{y}$, sobre todo, a la más decentedel pueblo alemán en abril del año 1945, apatía de las que muchos todavía no han conseguido liberarse en la actualidad (FALLADA 2017: 5).

Lo característico de esta reflexión radica en la posición intelectual de Fallada: la escritura como historia y experiencia de la desolación. Lo que interesa narrar es el derrumbe social e individual en medio de la catástrofe política, material y espiritual de Alemania y, a partir de ello, explorar la apatía, sentimiento este de la inercia y el pesimismo. La pregunta implícita que este fragmento del prólogo realza es: ¿cómo escribir después de la inhumanidad y del terror? El autor insiste en que la novela es "una historia de una enfermedad, por tanto, no una obra de arte" (FALladA 2017: 6). Este rechazo hacia noción de obra de arte es importante para destacar el intento de Fallada por otorgarle una voz a la experiencia del sufrimiento fuera del marco de lo artísticamente establecido. El terror político y la indigencia transforman radicalmente la experiencia del arte desde la negación de su propia idea: lo artístico nace de la inhumanidad en el momento en que se toma conciencia plena de la destrucción del sentido. Fallada niega la obra de arte para construir un nuevo arte, cuya fuerza radica en la construcción de un horizonte en medio de la devastación conceptual y material producto del nacionalsocialismo. En este sentido, el título del libro cobra mayor relevancia, ya que la pesadilla no solo hace alusión a lo vivido durante el nazismo, sino también a la plena consciencia de la ruina moral y la herencia del nazismo en la modernidad.

La primera parte del libro, cuyo subtítulo es La caída, comienza con un sueño del protagonista, el Dr. Doll. En el primer capítulo, titulado El primer engaño, Doll narra el sueño: está adentro de un cráter producto de una bomba. En ese cráter, imagina los sonidos de cuervos y la posibilidad de morir ahogado por el barro. El narrador describe la impresión de Doll en ese lugar de la siguiente manera:

Una tremenda última explosión lo había arrastrado al fondo cenagoso de ese cráter. No yacía solo. A pesar de que nunca oía sonido alguno ni veía nada como lo descrito hasta aquí, lo sabía: con él yacía allí toda su familia, y todo el pueblo alemán, y absolutamente todos los pueblos de Europa, tan desamparados e indefensos como él, atormentados por los mismos miedos (FALLADA 2017: 10).

La imagen del cráter simboliza la historia europea bajo las nuevas formas políticas nacidas a partir del imperialismo nacionalsocialista y fascista. Fallada va construyendo 
dicha historia de la catástrofe desde la intimidad (la familia) hasta la sociedad (los pueblos europeos), de manera que pone en evidencia la ruptura de toda forma social constitutiva de la civilización. El hundimiento de Doll, en este sentido, muestra el derrumbamiento de la noción de individuo en el marco de la experiencia inmediata de la posguerra. La inauguración de la famosa Stunde Null ("hora cero") nace de la imposibilidad, por parte de Fallada y, en última instancia, de la intelectualidad y una gran parte de la sociedad alemana de vislumbrar alguna vía para pensar el futuro y la condición humana. Por ello, cabe destacar que "The Zero Hour was the concept of a blank space, an emptiness that would either be filled in or left empty by the Germans themselves (BROCKMANN 1996: 14). La respuesta de Fallada ante ese espacio histórico "en blanco" generado por el quiebre de las concepciones políticas y sociales de la modernidad es la novela, en donde su propia escritura debate la verdadera existencia de dicha ruptura y pone en relieve la herencia del nacionalsocialismo en detrimento de una supuesta página en blanco histórica. En ese mismo capítulo, cabe destacar otra imagen que profundiza el desamparo que siente Doll, ya que desde arriba del cráter es observado por Los Tres Grandes: Churchill, Roosevelt y Stalin. La mirada de los Aliados es significativa, ya que simboliza la pesadumbre y la tristeza ante la historia alemana.

La "hora cero" implica una no-identidad, al mismo tiempo que afirma los horrores de la experiencia. El problema de la identidad, en la novela, es fundamental. Por un lado, Doll es la configuración ficticia del propio Fallada y sus experiencias; por otro lado, la identidad alemana se expresa, de manera concreta, en los vaivenes y sufrimientos del personaje. La génesis del yo (narrativo), en este sentido, está mediada por la disolución de los viejos paradigmas de la individualidad burguesa. El concepto sociológico de identidad del yo tiene un rol central para explicar el problema alemán durante la "hora cero". Con respecto a esta noción, se debe comprender que

La identidad del yo no es un rasgo distintivo, ni siquiera una colección de rasgos poseídos por el individuo. Es el yo entendido reflexivamente por la persona en función de su biografia. Aquí identidad supone continuidad en el tiempo y en el espacio: pero la identidad del yo es esa continuidad interpretada reflejamente por el agente. Esto incluye el componente cognitivo de la personalidad. Ser una $<$ persona $>$ no es simplemente ser un actor reflejo sino tener un concepto de persona (en su aplicación al yo y a los otros) (GIDDENS 1997: 72).

El sociólogo británico señala la importancia de poseer un concepto de persona para desarrollar la identidad. Este concepto se ve totalmente anulado en la novela. En el capítulo dos, titulado El otro engaño, se pone en evidencia la mirada que tienen los otros (en este caso, los soldados del Ejército Rojo) sobre los alemanes. En una descripción 
brutal por su concisión y su fuerza, Fallada escribe el encuentro de Doll y su familia con tres soldados soviéticos cuando entran a su vivienda. El intento de Doll de congraciarse con los soldados mediante un afectivo tovarich (camarada) se transforma en la prueba definitiva de la deshumanización de lo alemán ante los ojos de los otros. Después de este evento Alma, la esposa de Doll, menciona que la mirada de los soldados hacia ellos era como si estuviesen viendo a un muro o a un animal (FALladA 2017: 27). La despersonalización de los sujetos hasta convertirlos en mero objetos o animales viene aparejada con la historia concebida y vivida como una catástrofe. Los horrores de la guerra, al anular la noción de individuo, difuminan y terminan por borrar también el reconocimiento como sustento filosófico y cotidiano de los seres humanos. El reconocimiento de los soviéticos no se da en el marco de una afectividad, sino en la violencia cotidiana y en la brutalidad de la lucha política. En ese momento de tensión se condensa la historia de la deshumanización y la imposibilidad del reconocer: el menosprecio se instituye como la única respuesta posible ante el fracaso de la civilización. Vale destacar, por ello, que

Para el singular, la privación de sus pretensiones de derecho socialmente válidas, significa ser lesionado en sus expectativas de ser reconocido en tanto que sujeto capaz de formación de juicios morales; por eso, la experiencia de la desposesión de derechos va unida a una pérdida de respeto de sí, por consiguiente, de la capacidad de referirse a sí mismo como sujeto de interacción legítimo e igual con los demás. Lo que aquí por el menosprecio se le arranca de reconocimiento a la persona es el respeto cognitivo de una responsabilidad moral que, por su parte, solo puede ganarse trabajosamente en el proceso de la interacción civilizadora (HONNETH 1997: 163).

La pérdida de la interacción que la escena demuestra es característica del derrumbe del proyecto civilizatorio que el nacionalsocialismo enarboló como estandarte de una nuevo paradigma comunitario-estatal. La incapacidad de Doll y Alma de referirse a sí mismos anula la capacidad de crear una identidad a través de la reconciliación con la herencia política. Si la referencialidad hace aparición es por medio de la negatividad, es decir, por el despojamiento de la dignidad de ser humano. Por ello, lo que marca a ambos personajes es la herida y la culpa de existir. Esta concepción de la existencia que nace por la derrota se antepone claramente con la referencialidad jurídico-política del período nazi, en donde la estetización de la política enarbolaba una referencialidad a partir del asesinato y la exclusión del otro. Esta referencialidad homicida ${ }^{2}$ es lo que constituye el

\footnotetext{
${ }^{2}$ Se alude con este concepto a un modelo político a seguir. La referencialidad homicida hace alusión a la construcción de una idea de nación basada en la matanza indiscriminada como forma de construirse simbólicamente una identidad.
}

Pandaemonium, São Paulo, v. 24, n. 44, set.-dez. 2021, p. 400-420 
ANDRADE, R. - Der Alpdruck de Hans Fallada

período nacionalsocialista y que se ve expuesta, de manera desoladora, en la ya problemática noción de "hora cero". Donde se muestra con mayor ahínco esta revelación de la culpa de existir se halla en la siguiente reflexión de Doll, justo después del encuentro con los soldados soviéticos:

¡Todo lo que él había esperado desde hacía tanto tiempo del final de esa guerra se había derrumbado de manera vergonzosa ante la mirada de tres soldados rusos! ¡Él era alemán, es decir, pertenecía al pueblo más odiado y despreciado del globo! Estaba en un nivel más bajo que el de la tribu más primitiva del interior de África, que jamás podría causar al mundo tanta destrucción, sangre, lágrimas y desdicha como los que había provocado el pueblo alemán. De repente, Doll comprendió con claridad que posiblemente su vida no alcanzaría a ver la purificación del nombre alemán a los ojos del mundo, que quizá sus propios hijos y nietos tendrían que padecer el futuro la ignominia de sus padres. El espejismo de que bastaría una palabra, una mirada para entenderse con los otros pueblos, para expresar que no todos los alemanes eran cómplices, también ese espejismo se había desvanecido (FALLADA 2017: 29-30).

Si lo que configura la identidad es la mirada esta funciona, en este punto, como medio para mostrar el desplome del proceso civilizatorio. Aquello que forma parte esencial del acto mismo de socializar deviene en una acción de anulación. Además de este elemento, hay otro que se conjuga en la desolación de Doll: la infertilidad del lenguaje. Los dos discursos, el lingüístico y el corporal, se ven negados ante la necesidad de entablar una relación con el otro. El lenguaje, al perder su poder de humanizar, demuestra la situación-límite ante la cual los seres humanos son sometidos después del desprecio de la palabra producto del terror político y el desamparo de sentirse sin un lugar en el mundo. Lo que se desvanece es, entonces, la posibilidad de la redención histórica que se da a través de la palabra.

En el capítulo cuarto de la primera parte, titulado Los jefazos nazis, Fallada expone con mucha más fuerza el deterioro del proceso de civilización y la herencia nacionalsocialista aun viva entre la población. Al ser elegido alcalde del pueblo por parte de las autoridades soviéticas, Doll debe dar un discurso desde un balcón ante la población congregada. Cargado de profundo resentimiento, nota la hipocresía de la sociedad que, ante las nuevas autoridades, gritan jubilosos cuando semanas atrás lisonjeaban a las SS y saludaban fervorosamente con el "Heil Hitler". Justo al comenzar su discurso, se percata de la condición del pueblo alemán. La siguiente descripción que realiza el narrador es ilustrativa del momento:

Doll se inclinó hacia adelante y habló más deprisa, más alto. Habló de los tiempos que acababan de transcurrir, de sus beneficiarios, de culpables y simpatizantes. Y mientras continuaba hablando sin parar, mientras ellos, empecinados, como si ninguno pudiera darse por aludido, gritaban: ¡Bravo! Y, ¡Muy bien!, él reparo en lo que parecían haber cambiado sus conciudadanos. No eran solo sus caras pálidas, marcadas por el miedo, las 
preocupaciones, la congoja y las noches en vela; no eran solo aquellos que, para esquivar el primer embate, se habían pasado días en el bosque y cuyas ropas tenían ahora un aspecto descolorido y miserable... No, todos ellos tenían de pronto algo de miserable, de andrajoso, todos parecían haber descendido muchos peldaños en la escala social; por las razones que fuera, habían renunciado a una posición que habían mantenido durante toda su vida y se habían encuadrado, sin el menor pudor, entre el resto de desvergonzados. Y ese era su aspecto real, todos podían verlo; ese había sido siempre su aspecto cuando estaban solos. Ya no había en esos habitantes de un pueblo que soportaba su derrota sin dignidad, sin asomo de grandeza, nada que mereciera el esfuerzo de ocultarse (FALLADA 2017: 62).

En el nuevo tiempo, se vislumbra no solo las consecuencias materiales de la guerra y su intrínseca pobreza, sino también la condición de la identidad alemana que está desnuda ante la derrota. Entre un tono conmovido y de reproche, Fallada expone el vaciamiento de la existencia en el párrafo citado, es decir, la profunda miseria de lo alemán (y de lo humano al mismo tiempo) y la herencia de la política nacionalsocialista en cuanto a la carencia de cualquier valor ético. La novela, en este sentido, es la construcción de una apuesta ética frente a esa desnudez nacida del terror.

Tanto en el párrafo citado como en el transcurso de la novela, se evidencia ya un elemento central de la poética falladiana: el conflicto entre el individuo y la sociedad. La tensión de esto se halla en el mismo capítulo, en las distintas personas con las que Doll debe lidiar como alcalde, muchas de ellas antiguos pequeño burgueses oportunistas o afiliados al NSDAP. El que más resalta es el caso de Zaches, el hombre de negocios que prosperó con la desgracia ajena y el arribismo y cuyo final es la cárcel por ocultar un almacén provisto de alimentos y ropa en tiempo de penurias. Tanto este personaje secundario como otros que menciona Fallada son símbolos de la destrucción de lo social en pos de un individualismo exacerbado por el capitalismo imperialista. Las siguientes palabras del narrador son esclarecedoras en este punto:

Había muchísimas cosas que construir, regularizar, organizar y solucionar, y no existían prácticamente recursos: todo había sido saqueado y destruido por los nazis y las SS, incluso la voluntad de colaboración de los ciudadanos. Estos eran tan malvados, tan mezquinos, tan egoístas que solo pensaban en sí mismos, y era necesario darles órdenes, empujarlos, imponerles frecuentes castigos, Luego, a sus espaldas, ellos hacían todo lo posible para perjudicar al bien común y beneficiarse ellos mismos. Es más, a menudo incluso hacían daño por pura alegría ante el mal ajeno, sin el menor interés personal (FALLADA 2017: 65).

Este visible sadismo y destrucción de toda forma civil se compagina con la victoria, tanto del capitalismo como del nacionalsocialismo, en la vida social de Alemania. El quebrantamiento de la colaboración, elemento central en el proceso de civilización, es la hipóstasis de la negación del otro y de la identidad. Por ello, Doll siente 
que, a través de su trabajo, va perdiendo mucho más su ser interior y su intimidad (FALLADA 2017: 65-66). Frente a esta visión profundamente pesimista sobre la sociedad, lo único que mantiene a Doll con vida es el amor de Alma (su matrimonio) y su familia, cuyos lazos son siempre puestos a prueba durante la novela. Cabe destacar en este punto que

Marriage, in Fallada's view, is the most important link with the social world. Real citizenship is always gained by first passing the important tests set by the school of marriage, which is seen as the very source of the social order. The important part which the woman plays in this school has already been noted. Fallada's women always mantain a connection with the world, and the individual who refuses to be educated by the woman fails to find a way into society and to become one of its responsible members (SCHUELER 1970: 98).

Esta reflexión demuestra hasta qué punto la figura de la mujer y del matrimonio resulta importante para Fallada. No es fortuita, a la luz de esto, la elección del nombre Alma por parte de Fallada para designar a la esposa de Doll: a través del matrimonio y de lo femenino puede volver a hacerse una interioridad. Si la herencia del nacionalsocialismo es la desnudez, lo que no tiene contenido, la figura de la mujer da un sentido de pertenencia. Con esto, Fallada forma una Heimat a través de la escritura y del lazo social a través del amor. Llama la atención que sea a través de ambos elementos que pueda formar una ciudadanía verdadera. Lo ciudadano se configura, desde esta perspectiva, a través de la formación de un discurso que expone la herencia del terror, al mismo tiempo que hace un llamamiento a la esperanza por medio de la relación marital. La esperanza, entonces, estriba en aferrarse al impulso vital que provee la compañía de lo familiar: frente a la pérdida absoluta de la comunidad, surge lo concreto y particular como un intento de restaurar la civilización.

El capítulo cinco, titulado La llegada a Berlín, cuenta las peripecias del matrimonio en su primera instancia en las ruinas de Berlín después de abandonar el pueblo ante la enfermedad de Doll exacerbada por su función como alcalde. Alma, enferma y con una herida infectada, y Doll buscan ayuda a través de los escombros y la oscuridad. En este capítulo, el problema de la ciudad y la incidencia que tiene sobre la formación de una Heimat y de un sentido de pertenencia son característicamente ilustrativos. "Se sumergieron en el oscuro mar de ruinas, donde la luz de la luna no llega al fondo de los socavones de la calle. Avanzaban despacio, tanteando el camino. La calle estaba vacía, reinaba un silencio sepulcral en el que solo resonaban sus pasos" (FALLADA 2017: 87). Esta radiografía de la ciudad, en donde se compara con un mar, apunta a evidenciar la profundidad de la ruina de la identidad alemana. El mar, por su carácter 
ANDRADE, R. - Der Alpdruck de Hans Fallada

simbólico, implica lo inhóspito y al mismo tiempo el hundimiento, cuya materialización se halla en el pensamiento alemán y la imposibilidad de un futuro. La insistencia del narrador en estas descripciones del espacio y la ciudad muestran la relación entre la construcción de los personajes (Doll y Alma) como de las tensiones y la desilusión de un mundo perdido. En relación con esto, escribe Wolfgang Brylla sobre la ciudad en la obra de Fallada que

Der städtische Raum impliziert ein Rauschen, d.h. ein gewisses Störungsrepertoire, das je nach Figurenbeschaffenheit verschiedenartig abgerufen werden kann. Die Aufgabe des Erzählers besteht darin, diese Störungen und Irritationen aufzudecken und ihren Einfluss auf das Handeln der Protagonisten vorzuführen. Die Stadtkonflikte werden demgemäß nicht dialogisiert, sondern perspektiviert. Die Figuren sind nicht in der Lage, das eingefleischte und zementierte Stadtgerüst zu stören und aufs Neue zu modellieren. Eher ist es die Stadt, die selbst Störungen und Konfliktzonen generiert, mit denen die Subjekte sich auseinandersetzen müssen. Nicht die Figuren werden Herr über die Stadt, sondern umgekehrt (BRYLLA 2012: 202).

A la luz de esta reflexión, la pregunta apremiante es: ¿Cómo construir lo nuevo sobre la herencia de la barbarie? Las ruinas de Berlín exponen no ya las tensiones de la clásica metrópoli, sino la muerte y la defunción de una época. El silencio sepulcral que señala Fallada en la descripción ya citada atestigua dicha defunción. Al mismo tiempo, Fallada va de lo general (la ciudad) hacia lo particular (su propia casa en Berlín). Al haber pasado tanto tiempo fuera de la ciudad, la pareja pierde su casa en manos de la Oficina de Vivienda otorgandósela a otra mujer. La casa de ambos se mantiene en pie, aunque ya no les pertenezca más, lo cual acrecienta la condición de parias y desarraigados en una sociedad deshecha. A pesar de ello, el capítulo termina con un diálogo de Alma y Doll:

-En casa...-contestó ella, sonriendo con un pequeño atisbo de burla. Y de repente, muy arrepentida, añadió - : YYa verás, conseguiré un hogar magnífico para nosotros!

—Te creo — respondió Doll—. Un hogar magnífico... Lo espero con ilusión (FALLADA 2017: 98).

Este breve diálogo, conmovedor y lleno de esperanza, muestra la importancia de una Heimat para la consolidación de la vida individual y social. Inclusive con el tono irónico del principio, la ilusión de una nueva existencia se mantiene en el horizonte. Por ello, y a pesar del profundo fracaso que ambos personajes representan, Fallada reconoce en el hogar el espacio para comenzar a desprenderse de la historia de la apatía y la enfermedad. Por ello, la segunda parte de la novela es titulada por el autor como La curación.

En esta segunda parte, el capítulo noveno titulado Robinson es especialmente llamativo. En este capítulo Doll, después de pasar por los vaivenes de la Berlín destruida 
y caer, junto con Alma, en una profunda drogadicción logra entrar en su casa, mientras ella se encuentra internada en un hospital por sus heridas infectadas. En toda una descripción dedicada a la necesidad del hogar, Fallada se detiene en la fantasía infantil de Doll mientras este está cubierto por una alfombra sucia y polvorienta para protegerse del frío. La descripción de este sentimiento comienza de este modo:

En la fantasía, Doll se convertía en un Robinson en su isla desierta, pero un Robinson sin Viernes, un Robinson que detestaba cualquier visita de blancos y que sentía miedo ante la idea de ser «salvado» por ellos. Ese otro Robinson hacía todo lo posible por ocultarse de sus semejantes. Los árboles que rodeaban su cueva no podían ser espesos, ni el camino que la atravesaba muy tupido y recóndito. Lo que más le gustaba era inventarse un profundo valle, encajonado entre paredes rocosas altas y escarpadas, al que le llegaba por un largo y oscuro túnel de roca que podía condenarse fácilmente con piedras. El valle mismo, si bien contaba con un arbolado escaso, era impenetrable desde el cielo, de modo que ocultaba a Robinson de los aviadores (FALLADA 2017: 153).

Esta regresión hacia la infancia se profundiza mucho más cuando Doll se percata que "esa cueva rocosa o el valle profundo no simbolizaban otra cosa que el claustro materno, al que el amenazado deseaba regresar. Solo en él gozaría de calma y seguridad" (FALlADA 2017: 154). De nuevo se hace presente el conflicto entre el individuo y la sociedad. En esta huida hacia la infancia como modo de escape ante la miseria material y el desarraigo, Doll encuentra en lo materno la posibilidad de volver a sentirse plenamente en un lugar. Esta construcción de un nuevo lugar se manifiesta a través de la imagen de Robinson, expresión esta del hombre que debe erigir los elementos civilizatorios de los cuales ha sido despojado. A pesar de ello, ambos símbolos son ambivalentes. Lo materno funciona como vínculo amoroso para formar una comunidad basada en el principio de la pertenencia y el cariño, al mismo tiempo que la regresión hacia la cueva implica un nocontacto con lo social, es decir, la negación del lenguaje. En la cueva materna, el sujeto no habla, sino que se encuentra en estado embrionario, de manera que el silencio se transforma en un refugio. La fantasía regresiva de Doll, en una primera instancia, apunta a esta búsqueda de un silencio que acalle los conflictos de la herencia del nacionalsocialismo. En el caso del arquetipo robinsoniano, este se ve transformado por el deseo de Doll de no estar con nadie, volviendo a reforzar el silencio y el aislamiento del individuo frente a una sociedad desintegrada por el terror y la destrucción. Lo que Doll busca construir, a diferencia del Robinson clásico, es su interioridad despojada de toda referencia y sentido existencial. Si bien la regresión se presenta en términos negativos, es a partir de esta misma negatividad que Doll comienza a construirse un sentido de pertenencia más arraigado. Lo negativo, en este sentido, es la consumación del sufrimiento individual y nacional que apunta a reestablecer las bases civilizatorias a partir 
ANDRADE, R. - Der Alpdruck de Hans Fallada

de la no-identidad, haciendo de este modo un nuevo yo. Cabe decir por ello que "Die regressive Tendenz der Robinsonphantasie hilft Doll somit, in seiner Teppich-Urhütte einen neuen Selbstbezug zu entwickeln. Damit dieses Selbstverhältnis dann aber nicht in Stumpfheit und Apathie regressiv endet, muss er sich von seiner höhlenhaften Gemütsseligkeit aber auch wieder zu distanzieren lernen (VON PASSAVANT 2020: 189). Este distanciamiento, necesario ya que es el principio que le permite pensarse como persona en un entramado social, permite que Doll recupere el ímpetu por el trabajo y la vitalidad necesaria para pensar sobre su futuro y el de la sociedad alemana. Distanciarse, por ello, implica despojarse del arquetipo de Robinson asumiendo el fracaso de Alemania en todas sus dimensiones. El fracaso es, entonces, el impulso vital que lleva a Doll a volver a reencontrarse con la escritura.

El trabajo de Doll es el de la escritura. Como se ha podido observar, el problema del lenguaje y su incapacidad para comunicar está latente en la novela de forma recurrente. En el capítulo once, titulado Comienzo con una pelea, es problematizado de forma mucho más profunda dicha incapacidad. Después de la recuperación de Alma y su salida del hospital, ambos se proponen reconstruir sus vidas de forma consistente. Para ello, Doll decide visitar al viejo editor Völger, con la esperanza de encontrar algún tipo de trabajo. En un diálogo marcado por la reflexión sobre la condición del ser alemán y la literatura, Doll le responde al editor con la siguiente reflexión:

—Pero... No sé..., hasta ahora no he descubierto ninguna posibilidad—concluyó de repente- . Tal vez nunca vuelva a escribir un libro. Es todo tan desolador... ¿Quiénes somos los alemanes en este mundo destruido por nosotros mismos? ¿A quiénes vamos a dirigirnos? ¿A los alemanes, que no tienen ninguna gana de escucharnos, o a los extranjeros, que nos odian? (FALLADA 2017: 194).

Lo primero que llama la atención de esta reflexión es la pregunta por la identidad alemana en el contexto de una reflexión sobre la escritura y la literatura. A través de lo literario, de la incapacidad de concretizar el dolor a través de la escritura, surge la interrogación sobre la condición alemana. La pregunta que surge a raíz de esto es la siguiente: ¿cómo se puede escribir después de la apropiación, por parte del nacionalsocialismo, de la lengua alemana? La novela en sí misma es una respuesta ética ante tal pregunta. La curación de Doll no solo es interior, sino también un intento de curar la lengua de los horrores del terror político. A su vez, y de forma negativa, la desolación que señala Doll ya no solo tiene estrecha relación con las condiciones materiales, sino también con un vaciamiento del lenguaje. Visto desde esta perspectiva, el "¿quiénes somos?" se problematiza en el campo existencial y discursivo. Lejos de significar algo, 
esta pregunta por la identidad expresa lo contrario: la imprecisión y la sospecha de no poseer un horizonte que permita reconstruir la vida. En relación con esto, cabe destacar que

The ceasefire in Germany in May 1945 yielded a natural opportunity for German writers to examine the recent past years and contemplate the future of their art. In the early postwar years, many were drawn to the notion of a new beginning in literature. Others longed to return to traditions that seemed to have lost their efficacy. Only a few saw no need at all to alter their course. The extremists for change advocated a "clean sweap," demanding the rejection of sullied ideals and the purification of a language that had been corrupted by Nazism (BANGERTER 1988: 1).

En esta revisión de las consecuencias del nacionalsocialismo en la literatura, Fallada coloca, a través de su pregunta “quiénes somos los alemanes?”, el problema central de la reconstrucción de la lengua alemana. Esta reconstrucción conceptual y emocional de la lengua implica asumir el sufrimiento y la derrota como los orígenes de ese lenguaje sufriente. Los conceptos que nacen de este último se gestan a partir del horror y la esperanza. A pesar de esto (o, precisamente, por esto mismo) la otra pregunta que formula Doll cobra una dimensión mucho más profunda: “¿A quiénes vamos a dirigirnos?". Ni los alemanes quieren rememorar los sufrimientos y la pesadilla del terror político, ni los extranjeros quieren escuchar la voz de los derrotados, ya que ellos mismos son víctimas del odio y el desprecio generalizado. Visto desde esta perspectiva, el intento de Doll por volver a escribir tiene el fin de darle voz a los vencidos por la historia a través del dolor individual de un sujeto despojado de lugar y de lenguaje. La experiencia concreta de Doll es universal en tanto expone la vida social alemana: sin lengua y sin Heimat, no se puede pensar en un espacio comunitario. El nuevo comienzo en la literatura alemana hace de esta experiencia del ser despojado un elemento central de su reflexión, dándole forma más visible a la herencia nacionalsocialista que es la desnudez y la carencia de contenido. Esto se evidencia en el encuentro que tiene Doll con el escritor exiliado Granzow (personaje basado en Johannes R. Becher). Granzow busca volver a crear las bases de la literatura alemana y ofrecerle cobijo a los escritores más emblemáticos del momento que están con vida. A través de esta figura, Doll finalmente adquiere una casa para sí y para Alma. La impresión que señala el narrador de Doll hablando con Granzow evoca esos momentos de vacío. “Olvida que ha habido una guerra, una época anterior de infortunio, que es un hombre acabado y vacío, sin contenido... Que tampoco el altruista Granzow puede darle ese contenido, sino que tiene que crearlo él mismo, recuperar la fe, no solo en su propia persona sino también en sus compatriotas alemanes, en todo el mundo" (FALLADA 2017: 201). 
ANDRADE, R. - Der Alpdruck de Hans Fallada

La recuperación de la fe se encuentra en el capítulo final de la novela, titulado La curación. El comienzo del capítulo muestra a Doll escribiendo desde una habitación privada de un sanatorio para chicas prostitutas con enfermedades venéreas. Este retorno al sanatorio (en la novela las internaciones de Doll en ellos son frecuentes) es significativo: la enfermedad funciona como espacio de la escritura y la reflexión, al mismo tiempo que da lugar a la formación de una interioridad. El trabajo (la literatura), lo materno y el matrimonio son, para Fallada, los pilares que dan existencia a la vida civil. Después de las descripciones de los comportamientos de las chicas, que van de lo grotesco a lo erótico, Doll decide dar un paseo por la ciudad. Mientras tanto, Alma se encuentra en la provincia buscando los pocos enseres que poseen para volver a crear un hogar en la casa recién conseguida. La pobreza que ve lo llena de tristeza y hace que divida a la gente que observa entre los que ya no esperan nada y los que ya no se atreven a esperar nada (FALLADA 2017: 206). Esta imagen termina por ser contrarrestada por la llegada de Alma. La felicidad rebosa en el ambiente y la descripción del narrador demuestra el estado anímico de Doll:

La apatía lo ha abandonado de una vez por todas, ya no yace dentro del cráter de la bomba. Y no ha sido gracias a los Tres Grandes sino a que, misteriosamente, sus fuerzas para salir del cráter a fuerza de trabajo han aumentado, y ahora está arriba. ¡Da gracias a la vida, a la vida persistente, profanada una y otra vez, esplendorosa! Las naciones recobrarán la normalidad. También Alemania lo hará, esa amada y desdichada Alemania. El corazón enfermo de Europa volverá a sanar (FALLADA 2017: 229).

Este abandono de la apatía viene aparejado con la esperanza de un futuro a través del trabajo. En este último se cifra la posibilidad de la dignidad y de encausar la vida civil alemana hacia la construcción de la libertad y de la memoria. La salida del cráter evidencia ese ímpetu vital que se encuentra en el individuo para poder volver a pensarse en términos sociales. El final de la novela muestra a Doll debajo de un árbol mientras el viento ondea. Y el narrador señala, en una loa a la paz y a la dignidad de vivir, las siguientes palabras:

Apoyado unos instantes en ese árbol, escucha el susurro de las ramas. No es nada, solo aire en movimiento que provoca el rumor de las hojas. Nada más. Pero es suficiente. En los últimos años, nunca tuvo tiempo para detenerse debajo de un árbol y escuchar su susurro. Ahora lo tiene, porque hay paz... ¡Paz! Compréndelo en tu interior, hombre, ya no tienes que asesinar ni matar. ¡Las armas son innecesarias, de verdad ha llegado la paz! (FALLADA 2017: 230). 


\section{Conclusión}

Como se ha observado, 1945 implica un antes y un después en la sociedad alemana y europea. Hans Fallada captó esta ruptura de forma profundamente trágica (moriría en 1947, completamente desgastado por las experiencias que le tocó sobrellevar). La permanencia, la identidad y la escritura son las nociones que más fuerza tienen en la novela, sin descuidar el elemento central que la novela expone: el desamparo de los individuos después de un mundo perdido y arrasado. Este desamparo involucra la culpa de existir y la tristeza de constatar la barbarie heredada de la maquinaria genocida del nacionalsocialismo. La pregunta por la culpa, sintomática en la conciencia alemana en los primeros años de la posguerra, es desarrollada por Karl Jaspers en las siguientes palabras:

La cuestión de la culpa, más que una pregunta que nos formulan los demás, es una pregunta que nosotros nos formulamos. La respuesta que le demos en lo más íntimo fundamentará nuestra actual conciencia de lo que es y de lo propio. Es una cuestión de vida o muerte para el alma alemana. Solamente sobre ella puede tener lugar un cambio profundo que nos lleve a una renovación que parta de lo más originario de nuestra esencia (JASPERS 1998: 51).

Estas palabras, escritas en 1946 (el mismo año en que Fallada redacta Der Alpdruck), vislumbra el problema de la culpa en una parte de la intelectualidad alemana de los primeros años de la posguerra. A través de la novela analizada, Fallada ofrece una respuesta y una interpretación a esa conciencia de lo que es y de lo propio a través de la agonía de una época y el nacimiento de un nuevo episodio de la historia occidental. La renovación de lo alemán se da a través de la recuperación del lenguaje y de un sentido del hogar que abarque la comunidad de los afectos. En este sentido, la conciencia del horror y del sufrimiento forman parte de dicha renovación, necesaria para comprender un período oscuro de la historia alemana. Al mismo tiempo, esta recuperación del lenguaje implica, como se observó en el presente artículo, un intento por pensar a profundidad el lugar del escritor y un nuevo comienzo para la literatura alemana a través de su alterego

el Dr. Doll. Como señala Antonie Magen con respecto a esto

Die durch den Charakter einer kargen Bestandsaufnahme evozierten Ähnlichkeiten zu Günter Eichs programmatischem, 1945 entstandenem Gedicht Inventur, sind evident: Inszeniert wird hier wie dort eine persönliche Stunde Null, ein Neuanfang, an dessen Beginn nur das Notwendigste aus der Vergangenheit steht. Allerdings geht Fallada nicht über eine epische Beschreibung dieser neuen Poesie hinaus und bleibt damit der ästhetischen Tradition seines Erzählens verpflichtet. Ob die Erkenntnis, dass eine literarische Erneuerung stattfinden müsse, sich später tatsächlich zu einer neuen Ästhetik entwickelt hätte, muss Spekulation bleiben. Fallada starb am Beginn eines potentiellen Neuanfangs (MAGEN 2019: 154). 
ANDRADE, R. - Der Alpdruck de Hans Fallada

Si bien Fallada opta por la estética formal-tradicional de la novela, vislumbra a través del contenido las preocupaciones inherentes con respecto al nacionalsocialismo que tendrán las siguientes generaciones de escritores. En este sentido, debe pensarse Der Alpdruck como una novela central para comprender las relaciones entre el discurso literario, la memoria y los efectos devastadores del nacionalsocialismo. Fallada no especula, sino inicia ese nuevo comienzo. Por ello, el presente artículo expuso dichos problemas para abordar la historia y la necesidad del lenguaje como lugar no solo de la creación, sino también como un espacio para la reconstrucción de lo civil. La pesadilla de Doll termina con la loa a la paz del final, mas afrontar la herencia del nacionalsocialismo en Alemania sigue siendo de vital importancia para comprender los mecanismos sociales y culturales que se han construido desde 1945 hasta la actualidad. La novela como género, por su extensión y por su ritmo, permite dichas exploraciones. En este sentido Hans Fallada, el hombre despojado de todo, ofrece la oportunidad de estudiar, a través de esta novela, el principio de dichos mecanismos que tomarán distintos rumbos, tanto en la antigua República Democrática Alemana como en la República Federal de Alemania hasta la unificación. El alcance de esta obra, además de lo ya señalado, debe también comprenderse en su ámbito de re-edición y traducción. En inglés, la traducción se publicó en el año 2016. No es fortuita esta fecha si se toma en consideración el éxito que tuvo la adaptación cinematográfica de Jeder stirbt für sich allein a manos de Vincent Pérez. La recuperación paulatina de la obra de Fallada en inglés incentivó el comienzo de las traducciones (en algunos casos, enteramente nuevas) al español desde el año 2009. Der Alpdruck forma parte de esas novelas que aun no se encontraban traducidas a la lengua española, de forma que su publicación implica un acercamiento mucho más detallado de la obra falladiana y, en especial, del intento por parte de los escritores (Wolfgang Borchert sería otro ejemplo claro de esto) de darle a la experiencia del sufrimiento y la ruina una expresión cabalmente humana en medio de la inhumanidad. La actualidad de esta traducción a la lengua española, en este sentido, cobra una dimensión política: a través de la literatura hecha memoria los sujetos son testigos de los estragos causados por la mitificación ideológica. La ideología transformada en mito, es decir en pura abstracción, se concretiza a través de la destrucción de la existencia cívica e individual. Si se considera esto la importancia de esta novela radica en ofrecer una radiografía de la miseria que, a pesar de la pobreza y el desconsuelo, avista un lugar para la dignidad a través de lo más concreto de una persona: sus experiencias vitales.

Pandaemonium, São Paulo, v. 24, n. 44, set.-dez. 2021, p. 400-420 


\section{Referencias bibliográficas}

BANGERTER, Lowell. German writing since 1945: a critical survey. New York: Continuum, 1988.

BANNASCH, Bettina. Literatur der Inneren Emigration“. Begriffs- und diskursgeschichtliche Überlegungen. In: BANNASCH, B.; ROCHUS, G. (org.), Handbuch der deutschsprachigen Exilliteratur. Berlin: de Gruyter, 2013, 50-72.

BrockmanN, Stephen. German Culture at the "Zero Hour". In: BrockmanN, Stephen; TROMMLER, Frank (ed.). Revisiting Zero-Hour 1945: The Emergence of Postwar German Culture. Baltimore: American Institute for Contemporary German Studies, 1996, 8-36. (Humanities Program Report v. 1).

BRYLla, Wolfgang. Das Rauschen der Stadt. Zu Konflikträumen in Hans Falladas Berlin-Texte. In: CARSten, G.; ZimniaK, P. (ed.). Störungen im Raum - Raum der Störungen. Heidelberg: Universitätsverlag Winter, 2012, 185-202.

FalladA, Hans. Pesadilla. Trad.: Rosa Pilar Blanco. Madrid: Maeva Ediciones, 2017.

GIDDENS, Anthony. Modernidad e identidad del yo: El yo y la sociedad en la época contemporánea. Trad.: José Luis Gil Aritsu. Barcelona: Ediciones Península, 1997.

HonNETH, Axel. La lucha por el reconocimiento: Por una gramática moral de los conflictos sociales. Trad.: Manuel Ballestero. Barcelona: Crítica, 1997.

JASPERS, Karl. El problema de la culpa. Trad.: Ramón Gutiérrez Cuartango. Barcelona: Editorial Paidós, 1998.

Lethen, Helmut. Neue Sachlichkeit. In: Von Bormann, A.; Glaser, H.A. (ed.). Deutsche Literatur. Eine Sozialgeschichte. Band 9. Weimarer Republik - Drittes Reich: Avantgardismus, Parteilichkeit, Exil. Hamburg: Rowohlt Taschenbuch Verlag GmbH, 1983, 168-179.

LUKÁCS, György. ¿Reportaje o configuración? Observaciones críticas con ocasión de la novela de Ottwalt. Analisi. Quaderns de Comunicació, n. 28, 205-221, 2002.

MAGEN, Antonie. Fallada im Kontext der Nachkriegsliteratur. In: FRANK, G.; SCHERER, S.; FalladA, H. (org.). Hans-Fallada-Handbuch. Berlin; Boston: de Gruyter, 2019, 147156.

SCHUELER, Heinz Juergen. Hans Fallada: humanist and social critic. The Hague: Mouton, 1970.

VON PASSAVANT, Nicolas. Robinson im Bombentrichter - „Der Alpdruck“ (1947) und die Konfiguration von Hans Falladas Nachkriegspoetik. In: CARSTEN, G. (ed.). TraumaErfahrungen und Störungen des ,Selbst': Mediale und literarische Konfigurationen lebensweltlicher Krisen. Berlín: De Gruyter, 2020. 